\title{
A Study On the Expectation of Information Disclosure in University from the Perspective of Modern University System
}

\author{
Linlin Shang \\ College of Continuing education, South China University of Technology, \\ GuangZhou, GuangDong, China
}

Key words: university, Information disclosure, modern university system

\begin{abstract}
Information disclosure in university is a window for modern university to enter into society and to maintain social relations, a social attitude of following democracy and running university open, an act of configuring public resources. In the ecological governance system of modern university construction, information disclosure acts as a medium and push-hand. The realistic picture of information disclosure in universities of our country is not optimistic. It is necessary to explore and to consider the scientific path to promote the healthy development and the orderly promotion of information disclousure in universities from the angle of internal stakeholders and external stakeholders.
\end{abstract}

\section{现代大学制度视野下高校信息公开工作预期研究}

尚琳琳

华南理工大学继续教育学院, 广州, 广东, 中国

关键词：高校; 信息公开; 现代大学制度

中文摘要. 高校信息公开是现代大学走向社会, 建立和维系社会关系的一扇窗口, 是遵循民主、 开放办学理念的一种社会态度, 也是高校作为社会公共机构对公共资源进行配置的一种行为。 在现代大学建设的生态治理系统中, 信息公开发挥着重要的媒介和推手作用。当前我国高校 信息公开的现实图景并不乐观, 需要从内部利益相关主体和外部利益相关者的多元角度探讨 和思考促进高校信息公开工作健康发展和有序推进的科学路径。

\section{1. 引言}

高校信息公开是现代大学走向社会, 建立和维系社会关系的一扇窗口, 是遵循民主、开 放办学理念的一种社会态度, 也是高校作为社会公共机构对公共资源进行配置的一种行为。 当下社会, 高校信息公开的现实图景如何? 在现代大学制度建设中, 高校信息公开起到何种 推波助澜的作用? 应该如何科学地推进高校信息公开工作的开展? 这是高校工作者有待积极 思考的一系列问题。

\section{2. 高校信息公开在现代大学制度建设中的地位分析}

高校信息公开是现代大学制度的基本要求, 是现代大学建设的基础, 也是现代大学联系 
社会的重要媒介和窗口。

\section{1 现代大学建设的生态治理系统}

国家设立高等学校以实现社会公共利益为主要目的，赋予了其人才培养、社会服务、科 学研究、文化传承的重要使命。在现代大学的建设中, 这种使命的实施是在充分利用社会资 源并服务于社会、政治、经济、文化环境的基础上, 实现多元良性互动的。“建立现代大学 制度, 是新时期高等教育改革的方向, 发展的必然要求。建立现代大学制度的核心便是建立 合理的大学治理结构” ${ }^{[1]}$ 。现代大学制度是既遵循大学的内在逻辑, 又与现代社会相契合的 制度体系。因此, 高校只有在开放的、循环的、多维的系统中谋求与利益相关者的共同治理, 才能不断满足社会的持续需求，保持与时俱进的动态发展。

高校是社会多种因素综合作用下的产物。现代大学制度建设更是与传统“象牙塔”的保 守、孤立相对立的。因此, 只有观念的开放、资源的共享、信息的对称，才能实现高校向现 代大学的转变。现代大学建设是一个良性生态循环系统, 主要由大学的外部制度安排与内部 制度设计组成。由图 1 可知, 现代大学建设的生态治理系统内部利益相关主体主要包括高校 管理者、教师、学生, 而外部则由政府、社会和市场等利益相关者参与其中, 共同发挥作用。 在以高校为核心的基础上, 各利益相关者形成了一个有效沟通、相互依存、共同发展的生态 治理体系。

可见, 建设现代大学生态治理系统的基础是高校的开放、透明化办学; 根本是高校主体 性地位的确立; 主要推动力是高校内部各利益相关者的民主参与; 重要保障是高校外部各利 益相关者的协同互动。然而, 不论是内部还是外部利益相关者, 不管是以何种方式参与现代 大学的建设与治理, 都是必须建立在充分了解高校实情, 全面掌握高校办学状况基础之上的。 没有了解谈何参与? 唯有在掌握一定的信息资讯的前提下，才可以保证其参与行为的理性与 有效。

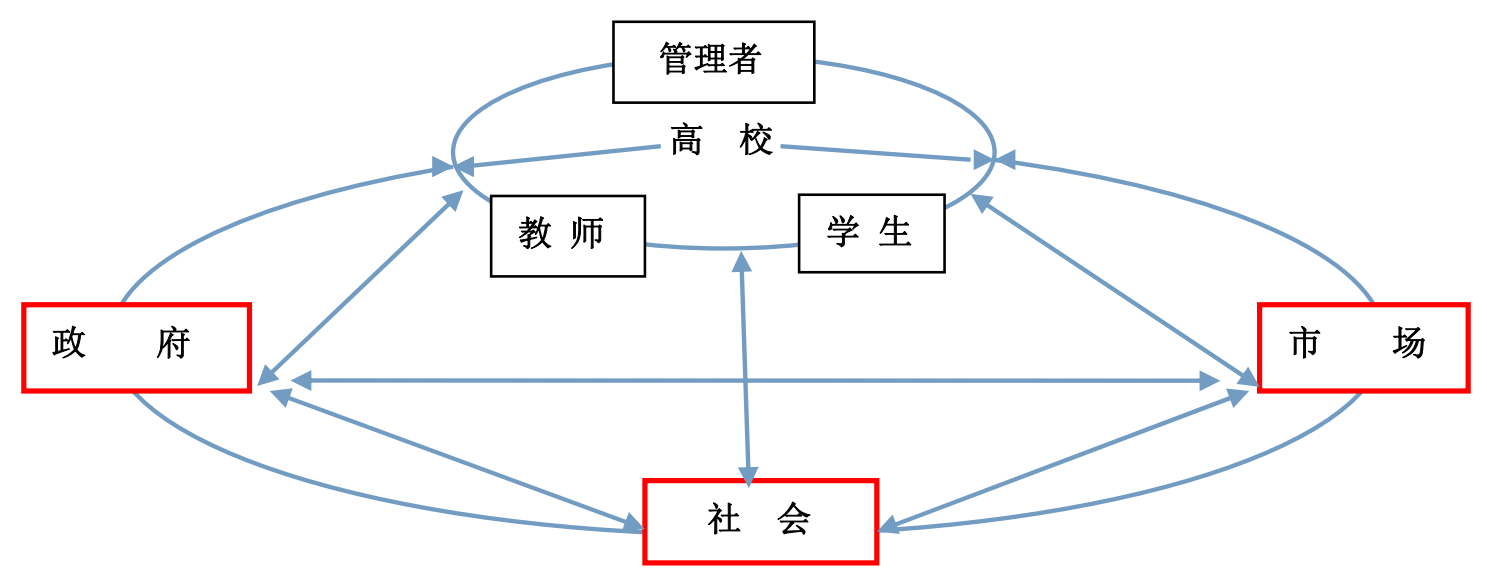

图 1 现代大学建设的生态治理系统

\section{2 高校信息公开在现代大学制度建设中的地位分析}

现代大学制度的根本就是充分发挥高校的主动性来适应和满足经济社会的发展, 从而达 到促进经济社会可持续发展的目的。因此, 学校自主办学、社会广泛参与、政府宏观调控、 市场适度调节是现代大学制度的关键要素。而要素功能实现的首要条件即为对高校信息的详 实认知。

2.2.1 高校信息公开是现代大学建立和维系社会关系的桥梁

现代大学制度要求高校依法面向社会开放办学。正如著名教育学者潘㻑元先生所言: “走 
向社会中心的大学需要建设现代制度，大学走进社会中心是历史的必然; 进入社会中心的大 学肩负着重要的历史使命, 应该成为社会经济发展的人才库、知识库、思想库和知识产业的 孵化器。” [2]作为依靠国家公共资源进行办学, 并提供公共服务的高校, 理应最大限度地向 社会提供相关信息，接受社会监督。与此同时，高校若想要在急剧变化的社会中寻求自我发 展的良机, 变输血为造血, 以实现自身教育资源效益的优化配置, 提升社会竞争力, 必然需 要向社会公开包括人才培养、科学研究、社会服务在内的各项信息, 以便社会做出有效选择。 信息透明度越高, 越有利于高校推销自己。信息公开是社会认知高校的基础、是与高校建立 双向互动的中介。社会只有在掌握必要信息的前提下才能有效介入高校治理与监督，从而推 动高校科学发展。

\subsection{2. 高校信息公开是现代大学自我发展和前进的助推器}

现代大学制度的核心内容为民主治校、学术自由。一方面, 民主管理是建立现代大学制 度的必要条件，而民主的前提是知情。知情权又必须建立在信息公开的基础之上。只有在知 情的情况下，教职工的参与权、表达权、监督权才有意义。这里的信息公开，包括过程与结 果的公开。另一方面，提高信息公开有效性，可扩大与畅通信息交流渠道，营造出学术争鸣 的良好氛围, 推动学术观点自由碰撞与智力资本合作创新。此外, 可通过公众参与权与监督 权的发挥, 吸纳多层次群体的见解、吸收多元化受众的诉求、听取多渠道的声音、接受全方 位的监督, 在利益相关者民主谋划下实现高校科学发展。因此，信息公开不单纯是高校单向 行为的信息输出, 而是高校与社会的双向互动。通过畅通的信息反馈渠道可以达到反向推动 现代大学自我发展的积极效果。

信息公开只是一种途径，最根本的是通过此途径推进高等教育体制的改革，去除高校行 政化, 预防腐败, 从而达到现代大学制度建立的目的。信息公开是高校开放办学的重要链条, 势必驱动高校与社会经济发展的主动契合，实现高校资源与外部社会资源的优化配置，如校 地合作、校企合作、校校合作等，最大化发挥现有各类社会资源的合理效用。反之，社会资 源反哺高校将会给予高校丰富的滋养。

\section{3. 高校信息公开工作现状分析}

2010 年，教育部颁布施行了《高等学校信息公开办法》（以下简称《办法》），第二条 明确规定 “高等学校在开展办学活动和提供社会公共服务过程中产生、制作、获取的以一定 形式记录、保存的信息，应当按照有关法律法规和本办法的规定公开”。自此，我国教育信 息公开真正走向了法制化建设的道路。那么，高校信息公开工作的落实状况如何呢？笔者拟 通过对 《办法》的深入解读, 结合目前 “985” 重点高校信息公开的具体做法与现实处境, 审 视当下高校信息公开的现实图景，并对高校治理的透明度作出评判。

\section{1 流于形式，公开不彻底}

《办法》对高校信息公开的范围进行了全面界定。《办法》第七条明确规定了高校应当主 动公开的包括学校概况、重大改革与决策信息、学生工作、教学管理、财务管理等在内的 12 类办学信息。此外，第十条对不予公开的高校信息作出了规定。《办法》的实施以立法形式 对高校信息公开工作给予了明确指导与理性约束。

《办法》施行以来，高校在政务公开的基础上，依据其指引陆续启动、规制与完善信息 公开工作。绝大部分高校依据自身情况编制了信息公开指南与信息公开目录，在开设传统渠 道的同时，利用信息网络技术搭建起信息公开网络平台，形式上贯彻了《办法》的规定。但 是, 由于 《办法》只是限于制度层面的规范, 缺乏法律的强制性, 造成高校信息公开内容中 有用信息相对缺乏，普遍存在内容空洞、言之无物、零散、不方便查询、时效性滞后等现象。

问题的形成，与作为信息公开主体的高校在认识和理念上的缺乏有很大的关系。由于信 息公开在高校行政实施中是一种自上而下的推进过程，没有制度践行的内生动力，所以高校 
是一种被动的接收, 缺乏主动的实施与坚持。

\section{2 限于纲要, 公开不深入}

由于《办法》只是限于纲要性的指导, 缺乏具体的可操作性的指引, 所以高校在信息公开 工作实施过程中程序化、规范化程度较低, 存在重要内容、敏感性内容公开不深入, 实施力 度弱的现象。

很多高校参照《办法》规定的公开范围制定公开目录, 其内容大多只是对相应项目下各 项规章制度、各项办学行为准则的公开, 而具体实施的过程如何、实际办学行为如何、提供 社会公共服务的过程怎样等大都没有公开。鉴于此, 在《办法》施行两年后, 教育部于 2014 年 7 月 29 日制定发布了《高等学校信息公开事项清单》（以下简称《清单》），对高校信息 公开内容作了更加具体的规定，分为 10 大类 50 条具体项目，其中对招生、财务、人事等热 点领域的信息作了特别明确的要求, 并提出更加严格的追责办法。同时, 《清单》要求 “各 高校应当编制学校上一学年信息公开工作年度报告, 对清单所列信息的公开情况逐条详细说 明。年度报告应当于每年 10 月底前向社会公布”。为此, 教育部于 2014 年 10 月 8 日专门发 布了《关于做好高校信息公开工作年度报告工作的通知》。但是, 截至 2014 年 10 月 31 日 18 时, 仍有超过一半以上的高校未更新信息公开年度报告, 且大部分高校信息公开网站仍未 涉及《清单》上规定的许多具体项目。随后, 教育部每年都有对做好高校信息公开年度报告 工作的要求, 但是对高校信息公开工作的推动效果并不显著。可见, 外在制度的约束只是一 种鞭策，内在主体意识的觉悟与体制的变革才是推动事件发展的根本。

\section{3 直于权力, 公开不全面}

目前，高校信息公开的现状与其过分 “行政化” 的管理模式有较大的关系。高校行政管 理者 (信息拥有者) 认为掌握信息是掌握了一种权力, 利用掌握的信息实现权力的放大和寻 租, 以此夸大教育公权力的范围。对于招生考试、财务管理、人事安排等与群众利益关系密 切的核心信息存在未公开或公开程度低的问题。从众多高校开展信息公开工作的现实来看, 基于多年 “阳光招生” 的推行、社会的监督及国家对违规事件的严惩，目前招生考试的公开 工作比以往有所改进, 但仍有待深入; 高校财政性资金使用与管理的信息公开远不能满足公 众的需求; 由于知识产权涉及国家及商业秘密，智力资本的公开也是匮乏的; 加之《办法》 规定 “学校规定的不予公开的其他信息” 可以不予公开, 助长了高校不予公开信息的正当性。

\section{4. 现代大学制度视野下高校信息公开工作的预期思考}

“现代大学制度的核心是重构高校、政府、社会三者之间的关系, 落实高校法人地位, 推 动大学依法自主办学制度的创新, 建立大学利益相关者普遍关心的参与机制。高校信息公开 是促进高校、政府、社会之间良性互动的桥梁和纽带, 是推动大学自治、依法办学、实现现 代大学制度良好治理的核心要素。” [3] 因此, 我们可以从内部利益相关主体和外部利益相关 者的多元角度探讨和思考促进高校信息公开工作健康发展和有序推进的科学路径。

\section{1 转变观念和意识, 激发信息公开的内生动力}

现代大学制度的建立, 即要改变高校依附于行政机关的被动地位, 提高高校办学的自主 性、独立性, 增强其作为独立法人和责任主体的意识, 推进高校管理向现代大学治理的转变。 现代大学的建设需要高校以独立自主、开放创新的姿态来回应社会, 进而催生其主动服务社 会发展的源动力。当高校获得主体地位和意识的时候, 就能体会到信息公开对于高校赢得良 好社会声誉和公信力的正向助力，进而产生出主动公开信息的内生动力和强烈意愿。

现代大学的治理不同于传统高校的管理, 其核心在于现代大学建设的生态治理系统中多 方利益相关主体的共同参与与谋划, 而非高校主体的单方管理。“在治理过程中, 各方主体 以公开、平等、透明、具有交互性的方式实现公共利益的扩大与增值, 其中所展现出来的是 
履行社会公共职能的一方所具有的负责任的、具有公信力的形象，以及对社会公众主体地位 的尊重。”[4] 由于高校处于现代大学治理体系中的核心位置, 这种治理过程的有效运行必然 需要建立在高校自主、开放的基础之上。在现代大学生态治理框架内, 现代大学想要赢得声 誉、获取资源、向前发展必然会主动公开信息，萌发信息公开的内生动力。高校信息公开行 为符合 “收益递增规律 (increasing return), 即信息被利用得越充分, 其产生的收益就越 大。[5]当高校信息有效、及时、全面地传递给社会公众并获得充分反馈时, 即很好地实现了 信息递增。

\section{2 完善制度和机制, 触发信息公开的外部驱动力}

高校信息公开工作机制中的 “机制”，即为治理机制，从管理学的角度分析，可包括运 行机制、动力机制和约束机制三个方面。运行机制指机构组织的活动方式和运行方式。动力 机制指机构组织因利益驱动、政令推动和社会心理驱使所产生的促进组织发展的动力。约束 机制指对权力、责任和利益进行限定与修正的行为及手段。因此，在探讨高校信息公开工作 机制时可以从以上三个方面进行把握与思考：

\subsection{1. 运行机制}

高校信息公开运行机制的建立可以从提高信息公开工作的规范化、流程化方面入手。目 前, 高校信息公开工作在公开范围、公开程度上的不足, 一定程度上与高校粗放式的信息数 据管理模式有关。由于信息数据的零散、分散，增加了信息数据集成管理的难度，因而对信 息公开工作造成了一定的障碍。为弥补 《办法》对高校信息公开规定的规范性、统一性与流 程化的不足, 教育部出台了更为细化的《清单》。《清单》显著增强了信息收集与管理的规 范性与统一性， “有利于形成稳定的预期和常态化的操作规程” [6], 可以有效减少人为因素 的影响。《清单》的出台, 无疑较好地契合与贯彻了党的十八届三中全会关于推进权力清单 制度和十八届四中全会全面推进政务公开的要求。《清单》对信息项目需要公开的事项进行 了逐一列举，覆盖了高校工作的各个方面，其中囊括了关系公众切身利益的项目，为信息公 开工作提供了更为直接的指引, 对于推进高校公共事务的开放式治理与依规治理起到了非常 积极的作用。然而, 自《清单》出台以来的成效来看, 显然还存在推动力度不足的问题。笔 者认为在信息公开的规范性上，除明确、细化公开的内容外，还应对不予公开的范围进行具 体限定，避免因为高校不予公开信息权利的过度放大而阻碍信息公开工作的有效推进。

\subsection{2. 动力机制}

信息公开的基本动力除高校的自觉自律外，还来自公共社会的力量，它是推动制度践行 与不断升级的主要动力。国家在推进现代大学建设的深层次改革中, 已在逐步尝试破除高校 的身份壁垒，采用以社会评价为核心的绩效评估作为对高校评价的重要标准。2015 年 10 月 以来推进的 “双一流” 的建设，就是拟按照具有中国特色的世界一流标准，采用第三方社会 评价, 切实做到竞争优选、专家评选、政府比选、动态笁选 [7]。原教育部副部长杜玉波曾提 出好大学的 “四个比度” : “办学定位对国家和区域经济社会发展需求的适应度; 领导精力、 师资力量、资源配置等对人才培养的保障度; 办学质量和效益对现代化建设的贡献度; 学生、 家长、社会对人才培养质量的满意度。” [8]评价一所大学的优劣不再只是凭上级主管部门的 遴选与认定，而是接受来自政府、社会、市场、教师、学生等利益相关体的综合评价。因此, 要成为受社会认可的高校, 高校需主动公开信息, 让社会各界全面了解自身, 才可能获得社 会的审慎衡量与客观评价，以获取外部资源的多元驱动。

\subsubsection{1 调动内部利益相关者的民主参与意识}

在高校内部，管理者为信息拥有者，而教师和学生为信息获取者。因此，调动师生对高 校事务的民主参与意识是信息公开的重要动力，也是高校提升自身治理能力的重要契机。高 校应主动向师生公开信息, 在保证师生知情权的基础上, 鼓励他们行使参与权, 发挥智囊和 精英的才智积极为学校的发展建言献策，有利于高校在准确、全面了解基层实际情况的基础 上做出客观、科学的决策，进而提升其内部管理水平。 


\subsubsection{2 提升外部利益相关者的权利共享意识}

外部利益相关者指政府、社会和市场。高校应确立自身的主体地位，通过信息公开博得 全社会的声誉和公信力。共同治理因素中，政府有效、合理的宏观决策; 社会丰富、充足的 资源支持; 市场灵活、敏锐的供需调节都需要建立在掌握高校办学信息的基础之上。因此, 提升外部利益相关者的权利意识, 发挥外部利益相关者的积极作用, 共同促进高校的有效治 理也是实现其主动公开信息的重要推动力。

\section{2.3 约束机制}

对权力、责任与利益的约束与规制可通过建立一系列的监督、评估、问责机制来实现。 就理论与实践而言, 自我对制度的践行力存在着局限。当制度变革触动变革主体既得利益的 时候, 其内在动力将大大折扣, 这也是若干制度在实施过程中形同虚设的主要原因。因此, 保障和监督高校信息公开工作的有效运行, 首先需建立由上到下、由外到内的督促与审查机 制。上级主管部门通过行政权威审查其落实情况; 社会各界通过與论压力确保其社会效应; 高校内部通过设立督察部门督促其有序开展; 高校师生通过民主参与负责其日常监督。其次 应建立客观、公正的 “阳光” 评估机制。引入第三方评估机构, 依法、依规设定评估指标体 系, 减少主观人为价值判断, 适时开展常规性、日常性评估, 注重考核信息公开工作的运行 效果, 包括信息的完整性、时效性、准确性、可获得性等, 找出工作中的亮点与问题, 并做 出总结, 为下一步工作提供参考。当客观评价占据與论主导时, 必然会引导信息公开工作的 积极有序推进。最后应建立权责明晰、追究与激励相结合的问责机制。由现代大学共同治理 体系中的利益相关者组成问责主体，依据评估结果对信息公开工作决策者、管理者和实施者 进行问责。“须把接受问责、确保权力的正确行使与被监督者的职位、荣誉、任用等挂钩” [9]，做到责任追究与激励机制相结合、精神激励与物质激励相结合。除职位、责任追究等, 高校的招生指标配给、财政拨款数量、社会评价高低等也与之挂钩, 必将对作为信息公开工 作主体的高校有极大地触动。

\section{致谢}

本文为华南理工大学人文社会科学研究项目《现代大学制度视野下高校信息公开工作机 制研究》成果

\section{Reference:}

[1] Jianchu Zhang, The University Governance structure under the Modern University system, Educational Review, 2009(5), pp.20.

[2] Maoyuan Pan,The university towards the Social Center needs to build Modern system, Journal of the National Institute of Educational Administration, 2001(2),pp.29-30.

[3] Huanhuan Xia , Information publicity in Colleges and Universities: the legal basis and realistic path of the Construction of Modern University system, Higher Education Research of Chongqing, 2015 (9) .pp.47.

[4][6] Expert interpretation List of Information Disclosure items in Colleges and Universities, China Education News, vol.2014-11-18.

[5] Ning Sun, information disclosure in government, Public policy agenda and participatory governance, China Administration, 2009 (2) .pp.66-68.

[7] Baosheng Chen, "double First-class" should be a combination of Chinese characteristics an World First-class, http://www.china.com.cn/lianghui/news/2017-03/12/content_40446671.htm. 
[8] Yubo Du, Vice Minister of Education:breaking down 985211 barriers to University identity, http://sh.qq.com/a/20141123/005345.htm.

[9] Hai Yan,Theory and practice of information disclosure in governent, Wuhai:Wuhai University Publisher,vol.2008. 